\title{
MULTIPLE-CLAUSE CONSTITUENT QUESTIONS: INTONATION AND VARIATION IN HUNGARIAN*
}

\author{
LOUISE MYCOCK \\ Faculty of Linguistics, Philology \& Phonetics \\ University of Oxford, Somerville College \\ Woodstock Road \\ Oxford OX2 6HD \\ United Kingdom \\ louise.mycock@ling-phil.ox.ac.uk
}

\begin{abstract}
When a question phrase bears a grammatical function in a subordinate clause but the interrogativity it introduces extends over a higher clause, there are two main possibilities in Hungarian: (i) the question phrase appears preverbally in the clause over which it takes scope, or (ii) the question phrase appears in the subordinate clause while the scope of interrogativity is indicated by the presence of another question phrase in the higher clause (the scopemarking construction). In order to understand the features shared by these two types of question and the ways in which they differ, this article explores the intonation of these types of multiple-clause constituent questions in Hungarian. The results of experimental investigation are reported and discussed, and the significance of these findings is evaluated in the context of wider typological variation in the formation of multiple-clause constituent questions.
\end{abstract}

Keywords: intonation, questions, scope marking, long-distance dependency, prosody

* This work was supported by Arts \& Humanities Research Council award 2003/101814 and a British Academy Postdoctoral Fellowship. I would like to thank Mary Dalrymple, Mária Gósy, Tekla Etelka Gráczi, Viktória Horváth, Alexandra Markó, Attila Mártonfi, Lenka Meszler, Gábor Olaszy, Tamás Péter Szabó, Nigel Vincent and two anonymous reviewers for their time, insights and patience. I am very grateful to all at the Kempelen Farkas Speech Research Laboratory of the Research Institute for Linguistics, Hungarian Academy of Sciences, Budapest. Their facilities, expertise and help were crucial in obtaining recordings of spoken Hungarian. 


\section{Introduction}

When a question phrase takes scope over a clause higher than the one in which it bears a grammatical function in Hungarian, two different strategies can be used to form a multiple-clause constituent ('wh') question. In this paper, I outline major features of the syntax (section $\mathbf{2}$ ) and intonation (section 3) of these two types of multiple-clause constituent question (CQ), discuss the significance of these aspects of their structure, and present an analysis of the scope-marking (partial 'wh' movement) construction (section 4) that is consistent with Staudacher's (2000) semantics and accounts for the similarities which exist between this construction and the CQ formation strategy referred to as 'wh' clausal pied-piping.

\section{The syntax of multiple-clause constituent questions}

\subsection{Constituent question formation strategy 1 : (multiple) syntactic focusing}

It is well established that in a regular CQ in Hungarian, a question word appears in the preverbal syntactic position associated with the discourse function focus (1). ${ }^{1}$

(1) (a) Interrogative

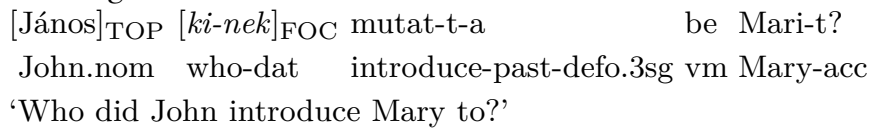

(b) Non-interrogative

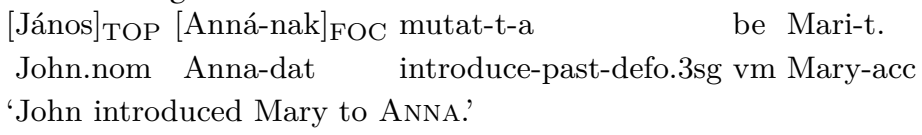

When a single question phrase bears a grammatical function in a lower clause, this CQ formation strategy can also be used, in which case the question phrase appears in the higher clause over which it takes scope, specifically in the immediately preverbal position associated with focusing. For example, in (2) the question word kinek 'who' appears in

${ }^{1}$ Abbreviations follow those in the Leipzig Glossing Rules and additionally include: defo = definite object; $\mathrm{H}=$ high tone; $\mathrm{H}+\mathrm{L}=$ bitonal falling pitch accent; $\mathrm{L}=$ low tone; and vm = verb modifier. 
focus position in the higher clause and is the indirect object of the verb bemutatta 'introduced' in the lower clause.

(2) $[\text { István }]_{\text {TOP }}[k i-n e k]_{\text {FOC }}$ gondol-ja, $\quad\left[\right.$ hogy $[\text { János }]_{\text {TOP }}$ Stephen.nom who-dat think-pres.defo.3sg that John.nom be-mutat-t-a Mari-t]?

vm-introduce-past-defo.3sg Mary-acc

'Who does Stephen think that John introduced Mary to?'

In a single-clause regular multiple $\mathrm{CQ}$, i.e., one which elicits a pair-list answer, ${ }^{2}$ question phrases form an indivisible preverbal group, consistent with them being syntactically focused $(3) .{ }^{3} \mathrm{I}$ will refer to this as CQ formation strategy 1: (multiple) syntactic focusing.

${ }^{2}$ I confine discussion and analysis to this type of multiple CQ, which represents the most frequent type in Hungarian (Lipták 2001, 101). See Lipták (op.cit., Chapter 3) for a review of other multiple CQ formation strategies available in Hungarian which are structurally and semantically distinct from those formed using Strategy 1.

3 There are analyses (e.g., Lipták 2001; É. Kiss 2002) which assume that only the final question phrase in the preverbal group occupies focus position in Hungarian; other question phrases are argued to occupy a higher syntactic position associated with a distributive reading. However, there is semantic, syntactic and intonational evidence which challenges this analysis. For example, Surányi $(2002,185)$ states that 'higher' question words need not be interpreted exhaustively in all cases, contrary to expectation if they occupy distributive quantifier position. Certain facts about syntactic distribution are also surprising if the non-final question word occupies distributive quantifier position: Surányi (2002) states that a distributive quantifier cannot intervene between two question phrases in a multiple CQ (i).

(i) ${ }^{*} \mathrm{Ki}$ mindenki-t mikor hív-ott fel?

who.nom everybody-acc when call-past.3sg vm

intended: 'Who phoned everybody when?'

(op.cit., 187)

Finally, if these question words are distributive quantifiers and the immediately preverbal question word alone occupies syntactic focus position, one would predict that the preverbal sequences distributive quantifier-focus and question word-question word in two different sentences would exhibit the same basic pattern of intonation. However, this is not the case: the distributive quantifier bears main stress in the former, but the immediately preverbal question word bears main stress in a multiple CQ (Mycock 2010). The location of main stress is indicated by bold in (ii) and (iii). (Main stress is discussed and exemplified in 3.5; example (10a) includes the pitchtrack for (iii).) 
(3) (a) $[\text { János }]_{\mathrm{TOP}}[k i-t]_{\mathrm{FOC}}[k i \text {-nek }]_{\mathrm{FOC}}$ mutat-ott be? John.nom who-acc who-dat introduce-past.3sg vm 'Who did John introduce to who?'

(É. Kiss 2002, 101)

(b) $[K i]_{\mathrm{FOC}}[k i-t]_{\mathrm{FOC}}[k i-n e k]_{\mathrm{FOC}}$ mutat-ott be? who.nom who-acc who-dat introduce-past.3sg vm 'Who introduced who to who?'

This straightforward relationship between syntactic focusing and CQ formation breaks down in the case of multiple CQs in which question phrases bear grammatical functions in a subordinate clause but the interrogativity they introduce extends over a higher clause. In such sentences, only a single question phrase can appear in the higher clause (2); if multiple preverbal question phrases occupy immediately preverbal position in the higher clause, the resulting CQ is ungrammatical (4).

(4) *Zéta $\quad[k i \text {-nek }]_{\mathrm{FOC}}[m i-t]_{\mathrm{FOC}}$ gondol-t, [hogy Emőke mond-ott $]$ ?

Zéta.nom who-dat what-acc know-past.3sg that Emőke.nom say-past.3sg

'What did Zéta think that Emőke said to who?' (Puskás 2000, 262)

To form a CQ in Hungarian in which the interrogativity introduced by multiple question phrases in a subordinate clause extends over a higher clause, a distinct CQ formation strategy is used: scope marking.

\footnotetext{
(ii) $[\text { Mindenki-t }]_{\text {DISTRIB }}[\text { János }]_{\text {FOC hív-ott }}$ fel.

everyone-acc John.nom call-past.3sg vm

'For every $x, x=$ person, John called $x$ ''
}
(iii) $\mathrm{Ki}$ ki-nek mutat-t-a be Mari-t?
who.nom who-dat introduce-past-defo.3sg vm Mary-acc
'Who introduced Mary to who?'

These data do not support a distributive quantifier analysis of non-final preverbal question phrases. Therefore, multiple preverbal question phrases are analysed as occupying multiple syntactic positions associated with focus in this article, as in (3b).

${ }^{4}$ There is a notable exception to this generalization. When the lower clause in this type of CQ is non-finite, that clause does not constitute a separate domain for certain syntactic phenomena in Hungarian, including syntactic focusing. Thus (i), in which the lower clause contains an infinitival verb form, is grammatical.

(i) István $[k i-t]_{\mathrm{FOC}}[k i-n e k]_{\mathrm{FOC}}$ akar [be-mutat-ni]?

Stephen.nom who-acc who-dat want.pres.3sg vm-introduce-inf 'Who does Stephen want to introduce to who?" 


\subsection{Constituent question formation strategy 2: scope marking}

Long-distance dependencies involving multiple question phrases can only be expressed using the scope-marking (partial 'wh' movement) construction, in which a question word appears in focus position in a higher clause and has the effect of 'extending the scope' of the multiple question phrases in the lower clause. I will refer to this as CQ formation strategy 2: scope marking. (The scope-marking question word $m i$ - 'what' appears in small capitals to distinguish it from other 'true' question phrases, which are given in italics.)

(5) $[\text { István }]_{\text {TOP }}[\mathrm{MI}-\mathrm{T}]_{\mathrm{FOC}}$ gondol, $\quad\left[\right.$ hogy $[k i]_{\mathrm{FOC}}[k i-t]_{\mathrm{FOC}}$

Stephen.nom what-acc think.pres.3sg that who.nom who-acc

hívott fel]?

call-past.3sg vm

'Who does Stephen think called who?'

The lower clause in this construction is a subordinate clause: it begins with the finite complementizer hogy 'that'.

The scope-marking construction is not reserved solely for longdistance dependencies involving multiple CQs; the lower clause may also contain a single question phrase, as in (6), cf. (2). ${ }^{6}$

(6) $[\text { István }]_{\mathrm{TOP}}[\mathrm{MI}-\mathrm{T}]_{\mathrm{FOC}}$ gondol, $\quad\left[\right.$ hogy $[\mathrm{János}]_{\mathrm{TOP}}[k i-n e k]_{\mathrm{FOC}}$

Stephen.nom what-acc think.pres.3sg that John.nom who-dat

mutat-t-a be Mari-t]?

introduce-past-defo.3sg vm Mary-acc

'Who does Stephen think that John introduced Mary to?'

The scope-marking construction may be used to extend the scope of a question phrase or phrases over more than two clauses, in which case the scope-marking question word $m i$ - 'what', whose position in a higher clause indicates the extent of interrogativity, appears in every clause which intervenes between the 'true' question phrase(s) in a lower clause and the highest occurrence of the interrogative scope-marker, as shown in (7).

${ }^{5}$ Contrast this with a sequence of autonomous interrogative clauses as in English What does Stephen think? Who called who?

${ }^{6}$ In Hungarian, the lower clause may also be a polar (yes/no) question, but for reasons of space, this type of interrogative scope-marking construction is set aside. 
(7) István $\quad[\mathrm{MI}-\mathrm{T}]_{\mathrm{FOC}}$ gondol, $\quad[$ hogy Mari

Stephen.nom what-acc think.pres.3sg that Mary.nom

[MI-T $]_{\text {FOC }}$ mond-ott, [hogy János $\quad[k i-t]_{\text {FOC }}$ hív-ott fell]?

what-acc say-past.3sg that John.nom who-acc call-past.3sg vm

'Who does Stephen think that Mary said that John called?'

A particularly interesting feature of the scope-marking construction crosslinguistically is that the embedding verb involved must be one that subcategorizes for a non-interrogative complement, such as gondol 'think' or mond 'say', but this must be paired with an apparently interrogative complement, as in (7). A non-interrogative complement in a scope-marking construction results in ungrammaticality (8).

(8) Verb which selects non-interrogative complement with non-interrogative complement

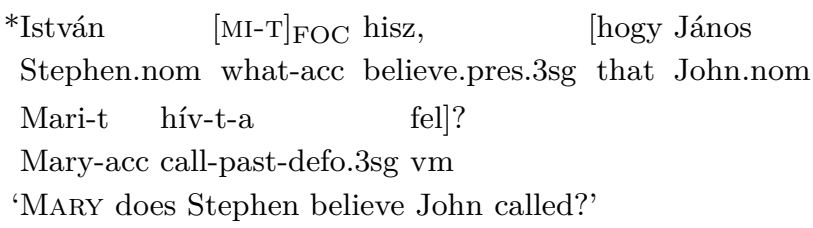

As the translation of (7) shows, the lower clause is not interpreted as an embedded CQ. This point, along with the fact that the verb in the higher clause subcategorizes for a non-interrogative in every other case, indicates that despite containing at least one question phrase, the lower clause is not in fact interrogative in a scope-marking construction.

Given the distinct syntax of these two types of CQs, it is interesting to compare their prosody to see which features they share and how they differ, and, in particular, to see if this provides insights into the exact nature of the scope-marking construction, whose syntax and semantics have been the subject of debate in the literature (e.g., Dayal 1994; Fanselow 2006; Staudacher 2000) but whose prosody has received little, if any, attention in terms of data collection and analysis. The results of experimental investigation into the intonation of both strategies used to form matrix, multiple-clause CQs in Hungarian are presented in section $\mathbf{3}$ and discussed in section 4 . 


\section{The intonation of multiple-clause constituent questions: experimental data}

\subsection{Method}

Examples of spoken Hungarian were elicited at three non-consecutive recording sessions consisting of smaller subsessions. Recording took place in a soundproof room at the Kempelen Farkas Speech Research Laboratory, Research Institute for Linguistics of the Hungarian Academy of Sciences, Budapest, Hungary, using a Stagg CM-5050 electret-condensor microphone and a Marantz PMD670 solid-state recorder. Recordings were made in mono with a sampling rate of $48 \mathrm{kHz}$; files were saved in .wav format.

\subsection{Consultants}

The consultants were four native speakers of Hungarian, two males and two females aged between 20 and 35, all of whom were born and raised in the Budapest area. None of the consultants reported speech or hearing difficulties.

\subsection{Materials}

Written instructions were given to consultants before each session began asking them to read aloud the material presented to them fluently, at as natural a speed and volume as possible. The stimuli were single sentences and two-sentence (question and answer) dialogues printed on separate cards and presented in pseudo-randomized order. Each target sentence/ dialogue was provided in isolation in order to elicit, as far as possible, 'outof-the-blue' utterances. Single sentences were recorded by one consultant in one subsession, while dialogues were recorded by two consultants in a separate subsession. A total of 180 sentences/dialogues were elicited in this manner at each recording session. 


\subsection{Analysis}

Target sentences were extracted from the original recording and saved as separate .aiff files. Pitch contours and $f_{0}$ values were analysed using Praat (Boersma-Weenink 2005). All measurements are in $\mathrm{Hz}$.

\subsection{Results}

For each type of multiple-clause CQ, a general pattern of intonation was identified in the data collected. ${ }^{7}$ The pitchtracks provided in this article represent a single token, i.e., one utterance produced at one recording session by a single consultant. However, each pitchtrack exemplifies the general pattern of intonation identified in the tokens elicited.

\subsubsection{CQ formation strategy 1: (multiple) syntactic focusing}

With respect to its intonation, CQs formed using Strategy 1, (multiple) syntactic focusing, exhibit the typical contour associated with a predicate $^{8}$ in a non-neutral sentence (Kálmán 1985b). ${ }^{9}$ A non-neutral sentence is defined in Kálmán et al. $(1986,130)$ as being "fairly marked semantically" and containing at least one operator. Non-neutral sentences thus include in a preverbal position a negative element, a distributive quantifier, an interrogative or non-interrogative focused constituent, or a combination thereof. The major distinguishing features of the intonation contour associated with the predicate in a non-neutral sentence are a single point of prosodic prominence ('main stress') which is followed by a low (L tone) plateau. ${ }^{10}$ The main stress in a non-neutral predicate bears a specific pitch movement: a sharply falling, i.e., $\mathrm{H}(\mathrm{igh})+\mathrm{L}(\mathrm{ow})$,

7 The discussion of prosody is confined to intonation here, given Olaszy's (2000) finding that changes in fundamental frequency, the acoustic correlate of changes in pitch, is the main carrier of prosody in Hungarian.

${ }^{8}$ In relation to a non-neutral sentence, predicate refers to the logical predicate which expresses some predication about the referent of the logical subject (the topic). (For the sake of clarity, I henceforth use the term embedding verbs instead of embedding predicates.)

${ }^{9}$ Neutral sentences and their prosody, which fall beyond the scope of this paper, are described and discussed in Kálmán (1985a) and Kálmán et al. (1986).

10 This low plateau has been claimed to be the result of stress reduction (e.g., Kenesei 1998a, 67-8) or stress eradication (e.g., Kálmán et al. 1986). 
pitch accent. ${ }^{11}$ In the case of a CQ containing a single question word, this $\mathrm{H}+\mathrm{L}$ accent appears at the left edge of the syntactically focused question phrase ('Q-FOCUS').

(9) Single clause, single CQ

$[\text { János }]_{\text {TOP }}[k i-n e k]_{\text {FOC }}$ mutat-t-a be Mari-t?

John.nom who-dat introduce-past-defo.3sg vm Mary-acc

'Who did John introduce Mary to?'

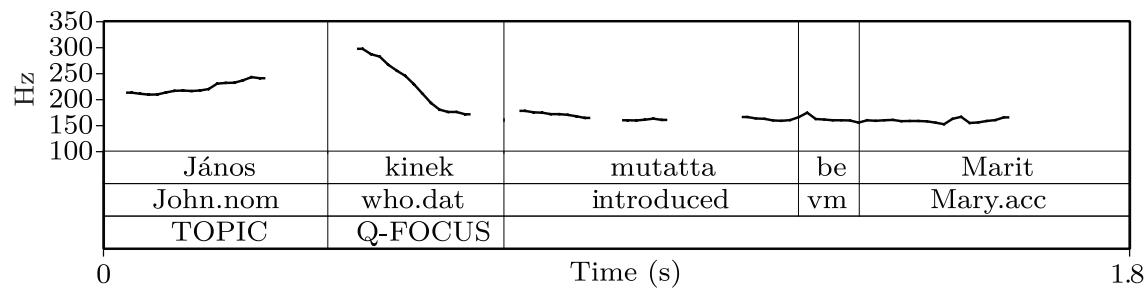

In a multiple CQ, only the final question phrase bears the characteristic sharp fall in pitch; other question phrases which appear preverbally bear a high $(\mathrm{H})$ monotone, regardless of their order relative to each other, cf. $(10 a-b) .{ }^{12}$ This high plateau is most clearly exemplified by non-final question phrases which consist of more than one syllable, as in (10b), and sequences of multiple non-final question phrases, as in (11).

(10) (a) Single clause, multiple CQ

$[K i]_{\mathrm{FOC}}[k i-n e k]_{\mathrm{FOC}}$ mutat-t-a be Mari-t?

who.nom who-dat introduce-past-defo.3sg vm Mary-acc

'Who introduced Mary to who?'

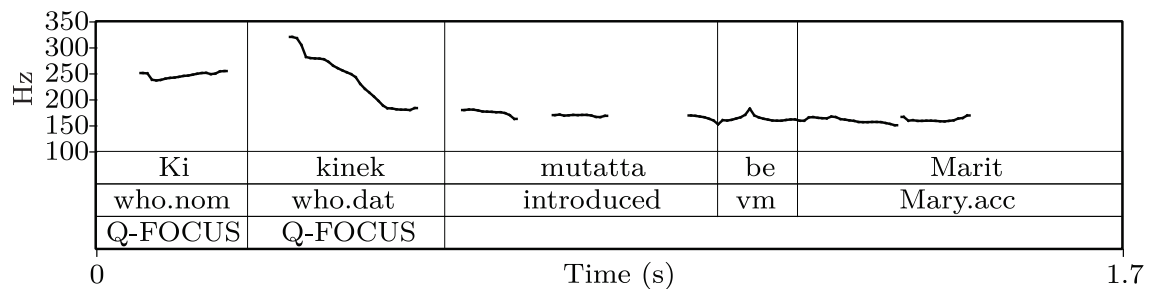

${ }^{11}$ In analysing this fall in Hungarian as a bitonal $\mathrm{H}+\mathrm{L}$ accent, this work accords with that of Varga $(2008,489-92)$, which contrasts with Grice et al.'s $(2000,169$ 75) analysis of falling contours in English and other languages as being composed of a separate $\mathrm{H}$ pitch accent and a $\mathrm{L}$ phrase accent.

12 Setting aside issues relating to animacy differences, Hungarian is a language which does not exhibit so-called Superiority effects (É. Kiss 1987, 60).

Acta Linguistica Hungarica 57, 2010 
(b) Single clause, multiple CQ

$[K i \text {-nek }]_{\mathrm{FOC}}[k i]_{\mathrm{FOC}}$ mutat-t-a be Mari-t?

who-dat who.nom introduce-past-defo.3sg vm Mary-acc

'Who introduced Mary to who?'

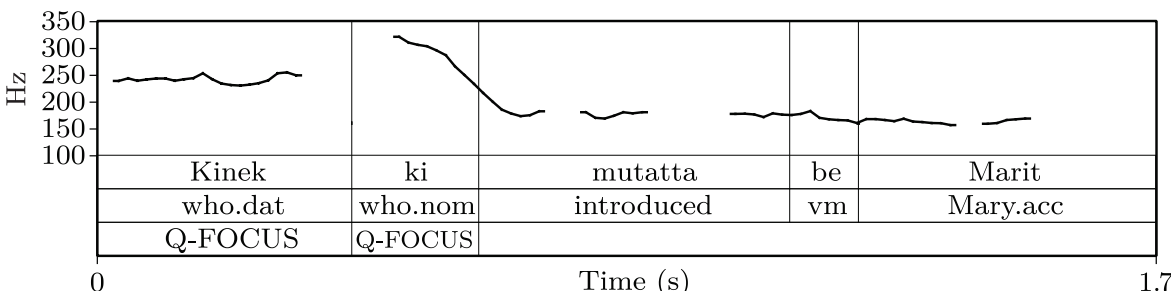

(11) (a) Single clause, multiple $\mathbf{C Q}^{13}$

$[K i-t]_{\mathrm{FOC}}[k i-n e k]_{\mathrm{FOC}}[k i]_{\mathrm{FOC}}$ mutat-ott be?

who-acc who-dat who.nom introduce-past.3sg vm

'Who introduced who to who?'

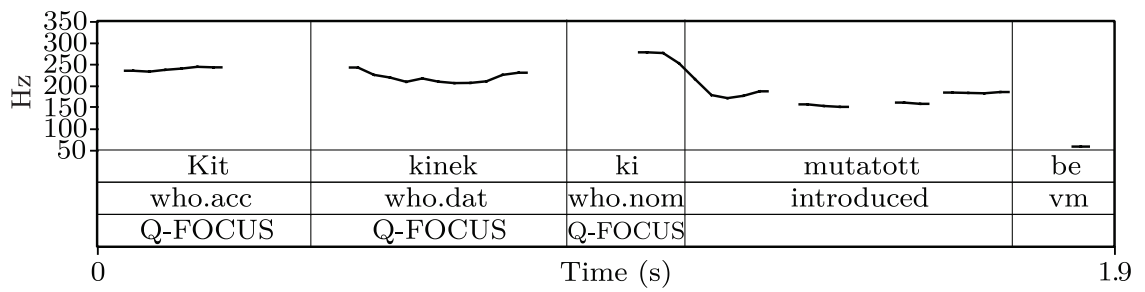

(b) Single clause, multiple CQ

$[K i \text {-nek }]_{\mathrm{FOC}}[k i-t]_{\mathrm{FOC}}[k i]_{\mathrm{FOC}}$ mutat-ott be?

who-dat who-acc who.nom introduce-past.3sg vm

'Who introduced who to who?'

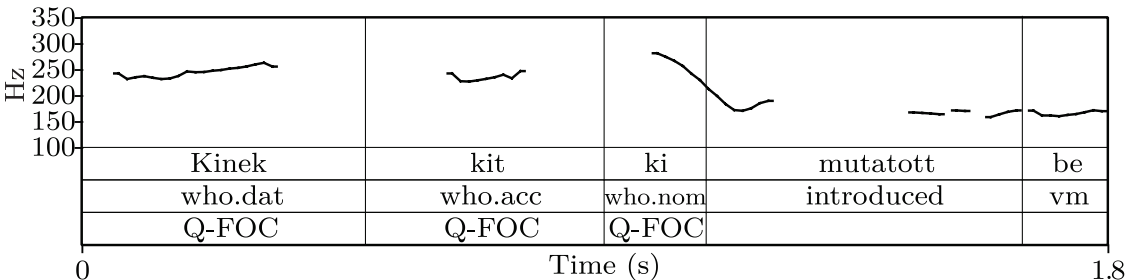

${ }^{13}$ In this pitchtrack, the L tone on utterance-final be is produced with creaky voice (laryngealization), a feature common to many speakers in those regions which have very low fundamental frequency (Beckman-Ayers Elam 1997). Shallow dips in the pitchtrack on question words are likely due to the pull of the baseline combined with the effect of a following $\mathrm{H}$ tone. 
The initial $\mathrm{H}$ monotone exemplified in these data is a feature of non-neutral predicates more generally (Mycock 2010). Data show that the widest scoping operator in a non-neutral predicate bears the $\mathrm{H}+\mathrm{L}$ accent $(\mathrm{Hu}-$ nyadi 2002; Mycock 2010). When this operator is not predicate initial, e.g., in $(10 \mathrm{a}-\mathrm{b}),(11 \mathrm{a}-\mathrm{b})$ and in (12) where the negative operator takes scope over the preceding universal quantifier, ${ }^{14}$ the $\mathrm{H}+\mathrm{L}$ accent is preceded by a $\mathrm{H}$ monotone. The prosodically prominent operator takes scope over any element that forms part of the preceding $\mathrm{H}$ plateau or the following L plateau within the same intonation contour. This is in line with Hunyadi's $(1985 ; 1999 ; 2002)$ general approach to operators, prosody and scope.

(12) Mindenki nem=dicsér-t-e Anná-t.

everyone.nom neg=praise-past-defo.3sg Anna-acc

'Not everyone praised Anna.'

(Kenesei 2009, 586, fn. 13)

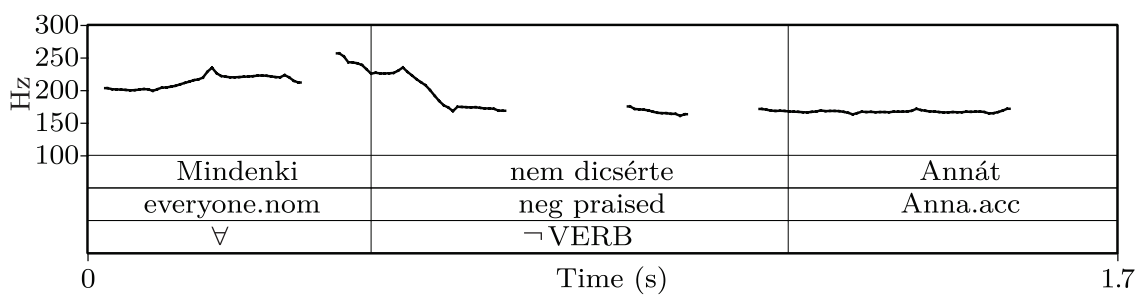

Thus the intonation contour associated with a non-neutral predicate is: (H) $\mathrm{H}+\mathrm{L} \mathrm{L}$.

In the case of a long-distance dependency, Strategy 1 exhibits the usual non-neutral predicate contour: the single question word in the higher clause bears the characteristic $\mathrm{H}+\mathrm{L}$ accent followed by a low plateau (13). This low plateau extends over the whole of the lower clause. This pattern is consistent with Hunyadi's (1985; 1999; 2002) proposals concerning the relationship between prosody and operator scope.

14 The universal quantifier in (11) occupies distributive quantifier position, i.e., occurs in the preverbal operator field. It is not a topic because universal quantifiers, as non-referential elements, cannot appear in topic position except when they are a contrastive topic. Mindenki 'everyone' in (11) does not bear the rising intonation contour associated with a contrastive topic (Gyuris 2003, 24). 
(13) Long-distance dependency: single question word
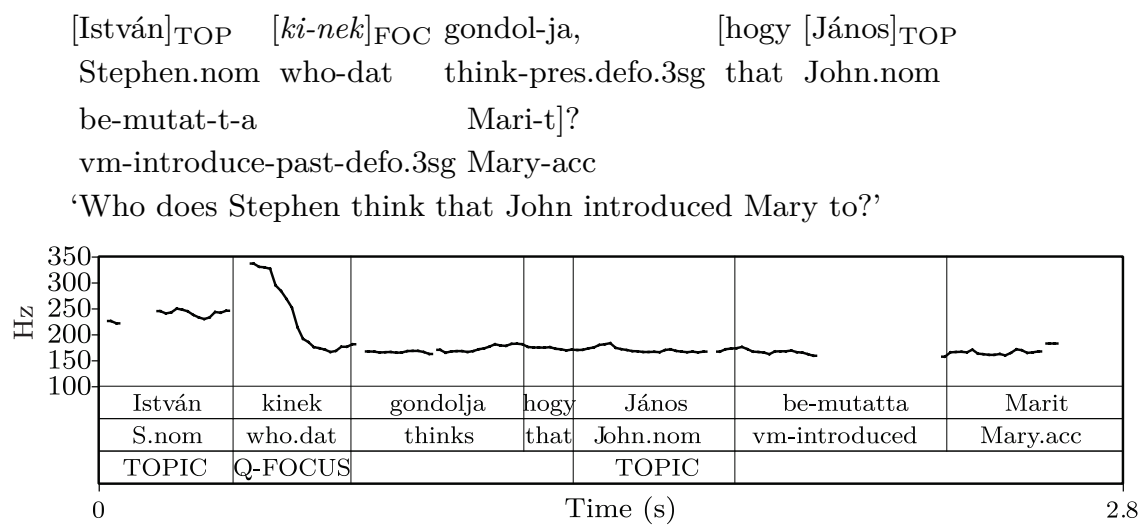

In this sentence, as in (9), (10a-b) and (11a-b), interrogative scope is not only signalled by the syntactic position which the question word occupies, the intonation contour associated with the predicate is consistent with indicating the extent of interrogativity as well, the immediately preverbal question word being the widest scoping operator (Mycock 2010).

Thus, the 'out-of-the-blue' long-distance dependency in (13) is associated with a single instance of the non-neutral predicate contour and this correlates with the scope of the widest-scoping operator, which is interrogative. Such data are in line with Hunyadi's (1985; 1999; 2002) approach to the prosody-syntax interface in Hungarian.

\subsubsection{CQ formation strategy 2 : scope marking}

The non-neutral predicate intonation contour is also a feature of scope marking (Strategy 2), though this type of CQ is associated with more than one occurrence of this particular pattern of intonation.

In a scope-marking construction, the lower interrogative clause exhibits the usual pattern of prosody found in a single clause CQ. When there is a single question word in the lower clause, as in (14), it is this element which bears the $\mathrm{H}+\mathrm{L}$ accent followed by the low plateau that is characteristic of the contour associated with a non-neutral predicate.

When more than one question word is present in the lower clause (15), the typical pattern of prosody, exemplified and discussed in section 
3.5.1, is observed; i.e., the final question word in the preverbal group bears the $\mathrm{H}+\mathrm{L}$ accent that is followed by a low plateau, while a non-final question word bears a $\mathrm{H}$ monotone.

(14) Scope marking: single question word in lower clause

$[\text { István }]_{\text {TOP }} \quad[\text { MI-T }]_{\text {FOC }}$ gondol, $\quad\left[\right.$ hogy $[\text { János }]_{\text {TOP }}$

Stephen.nom what-acc think.pres.3sg that John.nom

$[k i-n e k]_{\text {FOC }}$ mutat-t-a be Mari-t]?

who-dat introduce-past-defo.3sg vm Mary-acc

'Who does Stephen think that John introduced Mary to?'

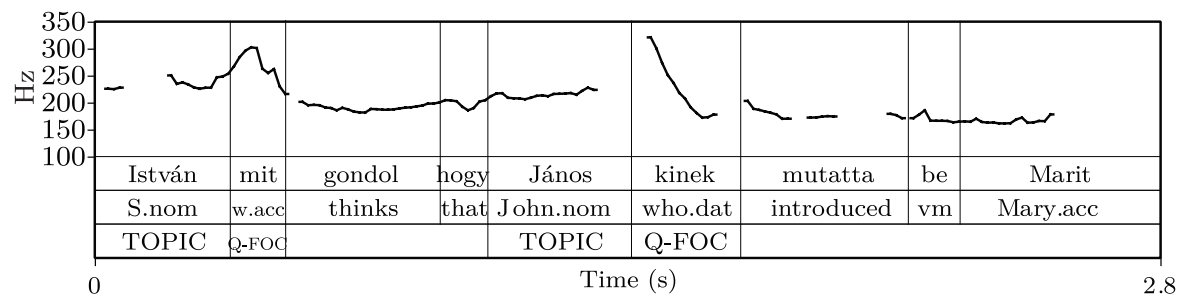

(15) Scope marking: multiple question words in lower clause
$[\text { István }]_{\mathrm{TOP}} \quad[\mathrm{MI}-\mathrm{T}]_{\mathrm{FOC}}$ gondol, $\quad\left[\right.$ hogy $[k i]_{\mathrm{FOC}} \quad[k i-t]_{\mathrm{FOC}}$

Stephen.nom what-acc think.pres.3sg that who.nom who-acc

hív-ott fel]?

call-past.3sg vm

'Who does Stephen think called who?'

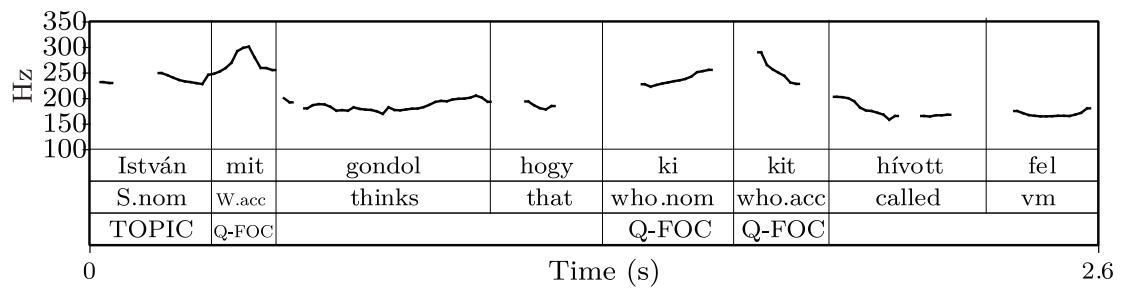

As for the prosody of the higher clause in the scope-marking construction, this too exhibits the usual intonation pattern for a non-neutral predicate. In (14) and (15), the interrogative scope-marker mit 'what' bears the $\mathrm{H}+\mathrm{L}$ accent and this is followed by the familiar low plateau. This intonation pattern is associated with every occurrence of the interrogative scope-marker in this type of construction (16). 
(16) $[\text { István }]_{\mathrm{TOP}} \quad[\mathrm{MI}-\mathrm{T}]_{\mathrm{FOC}}$ gondol, $\quad\left[\right.$ hogy $[\text { Ilona }]_{\mathrm{TOP}}[\mathrm{MI}-\mathrm{T}]_{\mathrm{FOC}}$ Stephen.nom what-acc think.pres.3sg that Helen.nom what-acc akar, $\quad\left[\right.$ hogy $[\text { János }]_{\text {TOP }}[k i-t]_{\text {FOC }}$ hív-j-on fell]? want.pres.3sg that John.nom who-acc call-subjunc-3sg vm 'Who does Stephen think that Helen wants John to call?'

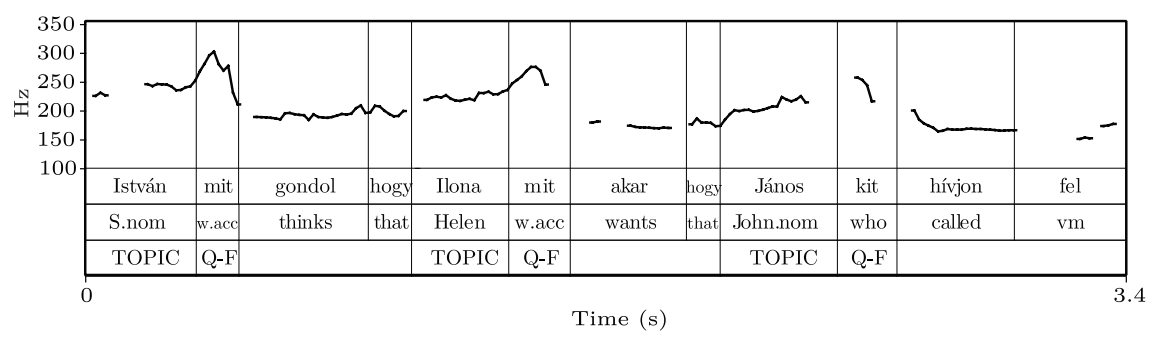

The extent of the plateau following the $\mathrm{H}+\mathrm{L}$ accent on the interrogative scope-marker is significant. Recall that in a long-distance dependency such as (13) the low plateau extends over the rest of the sentence and the entire non-neutral predicate contour correlates with the extent of interrogativity. In a scope-marking construction, the plateau following the interrogative scope-marker extends into a lower clause as far as the first 'true' question phrase or the next scope-marker, see (14). Any topic in a lower clause, e.g. János in (14), is part of the plateau, though this may be realized with a slight rise as the $\mathrm{H}$ tone of the following $\mathrm{H}+\mathrm{L}$ pitch accent is approached. Given the correlation between scope and the extent of the non-neutral predicate contour which has been observed (Hunyadi 2002; Mycock 2010), a scope-marking construction's intonation indicates that the scope of interrogativity extends from a higher clause into a lower clause up to the point where a separate non-neutral predicate intonation contour is initiated and thus that this construction includes multiple interrogative operators with distinct scopes. The start of any subsequent non-neutral predicate contour aligns either with a 'true' question word or another scope-marker rather than a clause boundary.

In summary, with respect to the intonation of multiple-clause CQs, comparison of utterances such as (13) and (14) reveals that the major difference between Strategy 1, (multiple) syntactic focusing, and Strategy 2 , scope marking, is that the latter involves more than one non-neutral predicate contour. This indicates that a scope-marking construction includes multiple (interrogative) scope-taking elements with distinct scopes that do not coincide with clause boundaries in the syntax. 


\section{Discussion}

As stated in 3.5.2, a correlation has been observed between the extent of the non-neutral predicate intonation contour and the scope of the widest-scoping operator in Hungarian (Hunyadi 2002; Mycock 2010). In the case of a long-distance dependency like (13), a single instance of the relevant contour is involved and this correlates in a straightforward way with the (matrix) scope of the interrogative element (i.e., the question phrase in the higher clause). By contrast, the scope-marking construction exemplified by (14) involves two occurrences of the non-neutral predicate contour, meaning that this CQ's intonation is consistent with there being two interrogative elements with distinct, but possibly related, scopes: (i) the scope of the interrogative scope-marker $m i$ - 'what', which is present in the higher clause, and (ii) the scope of the question phrase(s) in the lower clause.

To account for this pattern of intonation, and to account more generally for the apparent violation of the embedding verb's usual subcategorization requirements, I propose that rather than being an embedded $\mathrm{CQ}$, the lower clause in a scope-marking construction is a non-interrogative which contains a $\mathrm{CQ}$ and as a consequence is a $\mathrm{CP}$ which has the status of a question phrase. This question phrase is clausal rather than, for example, nominal, but it can take scope over a higher clause just like any other type of question phrase (e.g. NP which man, AP how far). A CQ which includes a question clause is unusual in crucially involving co-dependent interrogatives. One CQ is part of the lower non-interrogative question clause, which means this clause has question phrase status without being a CQ itself. This question clause may take scope over a higher clause thus forming another CQ, one whose interpretation is in turn dependent on the meaning of the CQ in the question clause.

This proposal is in general accord with the semantics of interrogative scope marking outlined in Staudacher (2000). Staudacher (2000) claims that the co-dependency established in a scope-marking construction requires that a proposition which constitutes an answer to, for example, (14) is a possible answer to the CQ in the lower clause (Who did John introduce Mary to?) which the subject of the higher clause (Stephen) thinks/believes. (14) could therefore be more accurately translated as 'Of which proposition does Stephen think that it is an answer to the CQ Who did John introduce Mary to?' 
Staudacher's (2000) analysis is supported by data such as (17) and (18), which show that comparable CQs, formed in accordance with Strategy 1 and Strategy 2 respectively, are not equivalent.

(17) Syntactic focusing (Strategy 1)

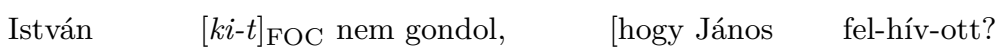

Stephen.nom who-acc neg think.pres.3sg that John.nom vm-call-past.3sg

'Who doesn't Stephen think that John called?'

\section{(18) Scope marking (Strategy 2)}

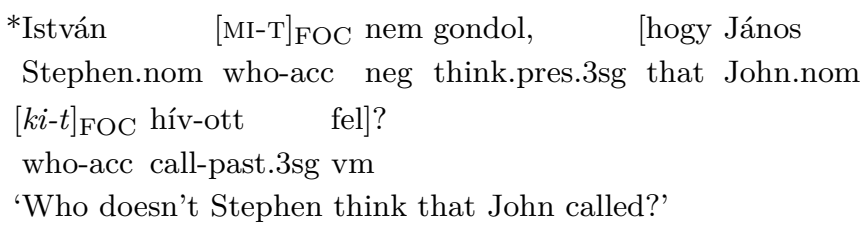

The scope-marking construction in (18) can be paraphrased 'Which proposition that is a possible answer to the CQ Who did John call? is not thought by Stephen?' Such a CQ would usually be unanswerable according to Staudacher (op.cit., 203-5) because an answer would have to be an exhaustive specification of all and only the possible complete answers to the CQ in the lower clause which Stephen does not think. The meaning of its Strategy $1 \mathrm{CQ}$ counterpart (17), on the other hand, can be paraphrased 'Who is it true to say that Stephen does not think of that person that John called him/her/them?', a question to which there is a unique answer. The contrast in grammaticality between a negative scope-marking construction and its Strategy $1 \mathrm{CQ}$ counterpart is thus accounted for by the semantic differences between the two constructions, as proposed by Staudacher (2000).

The Staudacher (2000) co-dependency analysis is supported by the distinct intonation patterns associated with the two types of CQs considered in this paper. Strategy 1 involves only a single instance of the non-neutral predicate intonation contour, and this correlates with the scope of the widest-scoping (interrogative) operator, e.g., the question phrase kinek 'who' in (13). The scope-marking construction, on the other hand, involves two of these intonation contours, consistent with two distinct interrogative scopes being indicated. The first contour correlates with scope over the higher clause, while the second contour indicates interrogative scope within - but crucially not over - the lower clause. For example, in (14) the intonation contour initiated by the $\mathrm{H}+\mathrm{L}$ accent on 
the scope-marker mit 'what' correlates with the matrix scope of the question clause, while the intonation contour initiated by the $\mathrm{H}+\mathrm{L}$ accent on the 'true' question phrase kinek 'who' correlates with the interrogative scope which is internal to the lower question clause.

What remains to be accounted for is the precise status and function of the scope-marker $m i$ - 'what' in the higher clause. I argue that the key to understanding the part that the interrogative scope-marker plays in a scope-marking construction is the fact that a clause cannot occupy the syntactic position associated with focus and therefore a question clause cannot be focused in the usual way in Hungarian. Compare (19), an example from Basque, and (20). In Basque, it is possible for a clause to occupy the syntactic position associated with focus (19), whereas in Hungarian this is not possible (20).

(19) Basque

[[Jon etorriko d-ela bihar $]_{\text {FOC }}$ esan diot Mireni]

Jon.nom come aux-that tomorrow say.past aux Mary.dat

'That it is Jon that will come tomorrow have I told Mary.'

(Ortiz de Urbina 1990, 199)

(20)*János [csak [hogy nyíl-ik az ajtó] ]FOC vett-e észre.

John.nom only that open-pres.3sg the door.nom notice.past-defo.3sg vm

'John only noticed that the door was opening.'

(É. Kiss 2002, 231)

Just as a declarative sentence can involve syntactic focusing of a clause in Basque, so can a CQ, in which case the focused clause contains at least one question word; i.e., it is a question clause. This construction is often referred to as 'wh' clausal pied-piping and in Basque it involves situating the question clause in immediately preverbal position in a higher clause, focusing it syntactically in line with this language's regular CQ formation strategy. Thus, in a matrix CQ such as (21), the question clause's syntactic position indicates that the matrix clause is part of the scope of interrogativity.

(21) Basque

[[Nor etorriko d-ela bihar $]_{\text {FOC }}$ esan diozu Mireni]?

who.nom come aux-that tomorrow say.past aux Mary.dat

'Who did you say to Mary will come tomorrow?' (Ortiz de Urbina 1990, 199) 
Significantly, 'wh' clausal pied-piping is only possible in Basque when the embedding verb is one which usually subcategorizes for a non-interrogative complement (Ortiz de Urbina 1990, 199-200); i.e., the same restriction on the embedding verb holds for this CQ as for the scope-marking construction. This strongly suggests that the scope-marking construction and 'wh' clausal pied-piping are examples of the same type of CQ. I claim that the difference between Basque and Hungarian is whether a question clause can be focused in the same way as other non-clausal question phrases. Evidence for this position comes from data such as (19) and (20), which show that while a clause can occupy focus position in Basque, this is not the case in Hungarian. ${ }^{15}$ Therefore, in Hungarian if a question clause is to take scope over a higher clause, it must be focused by some other means.

I propose that a question clause in Hungarian can only be focused and take scope over a higher clause 'by proxy', i.e., by being associated with a focused interrogative expletive element, viz. the scope-marker $m i$ - 'what'. Discourse expletives have been identified in several languages. For instance, Lecarme (1999) identifies a focus expletive in Somali. Indeed, Kenesei (1998b, 28) refers to scope-markers for quantifiers in Hungarian, including the interrogative scope-marker, as "expletive-like items". An expletive analysis of this element is supported by the fact that $m i$ - 'what', which appears to be the minimal specification of a question word, is possible only when it is necessary (i.e., to 'focus by proxy' a question clause), has no semantic content of its own, and has no independent reference, features it shares with other expletive elements.

No new semantic mechanisms or contributions need be posited to account for the scope-marking construction (Strategy 2). According to the approach I have outlined, Hungarian is a language that consistently employs one CQ formation strategy, which involves focusing question phrases, and has an interrogative expletive in its lexicon. The scope-marking CQ construction is simply a case of Hungarian using different means ('focus by proxy' involving an interrogative expletive) to the same end (focusing of a question phrase) because, unlike other non-clausal question phrases, question clauses cannot be syntactically focused in this language.

15 The question of why Basque should permit syntactic focusing of a clause while Hungarian does not must be left for future research. 


\section{Conclusion}

In this paper, I have examined the syntax and intonation of two types of multiple-clause CQs: (multiple) syntactic focusing (Strategy 1) and scope marking (Strategy 2). I have proposed that the scope-marking construction represents a strategy used to focus a question clause, rather than an alternative CQ formation strategy in its own right. This is, I contend, an example of Hungarian exploiting its resources to achieve an end which may be achieved by different means in other languages, for instance by 'wh' clausal pied-piping in Basque. Once the possibility that a clause (CP) can be a question phrase like any other XP is admitted, languagespecific and cross-linguistic data relating to these constructions can be accounted for and additional mechanisms of interpretation or syntactic structure prove to be unnecessary.

\section{References}

Beckman, Mary E.-Gayle Ayers Elam 1997. Guidelines for ToBI labelling (Version 3). Retrieved 23 October 2009, from http://www.ling.ohio-state.edu/research/ phonetics/E_ToBI/.

Boersma, Paul-David Weenink 2005. Praat: Doing phonetics by computer. (Version 5.1) [Computer program]. Retrieved 31 January 2009, from http://www.praat.org/

Dayal, Veneeta 1994. Scope marking as indirect wh-dependency. In: Natural Language Semantics $2: 137-70$.

É. Kiss, Katalin 1987. Configurationality in Hungarian. Reidel/Akadémiai Kiadó, Dordrecht/Budapest.

É. Kiss, Katalin 2002. The syntax of Hungarian. Cambridge University Press, Cambridge.

Fanselow, Gisbert 2006. Partial wh-movement. In: Martin Everaert-Henk van Riemsdijk (eds): The Blackwell companion to syntax, 437-92. Blackwell, Malden MA \& Oxford.

Grice, Martine-Robert D. Ladd - Amalia Arvaniti 2000. On the place of phrase accents in intonational phonology. In: Phonology $17: 143-85$.

Gyuris, Beáta 2003. The semantics of contrastive topics in Hungarian. Doctoral dissertation, Eötvös Loránd University (ELTE), Budapest.

Hunyadi, László 1985. Operators, scope and linear order. In: Kenesei (1985, 39-52).

Hunyadi, László 1999. The outlines of a metrical syntax of Hungarian. In: Acta Linguistica Hungarica $46: 69-94$.

Hunyadi, László 2002. Hungarian sentence prosody and Universal Grammar. Peter Lang, Frankfurt am Main.

Kálmán, László 1985a. Word order in neutral sentences. In: Kenesei (1985, 13-23).

Acta Linguistica Hungarica 57, 2010 
Kálmán, László 1985b. Word order in non-neutral sentences. In: Kenesei (1985, 25-37).

Kálmán, László - Gábor Prószéky - Ádám Nádasdy-C. György Kálmán 1986. Hocus, focus, and verb types in Hungarian infinitive constructions. In: Werner AbrahamSjaak de Meij (eds): Topic, focus, and configurationality, 129-42. John Benjamins, Amsterdam.

Kenesei, István (ed.) 1985. Approaches to Hungarian 1 (Data and descriptions). JATE, Szeged.

Kenesei, István 1998a. Adjuncts and arguments in VP-focus in Hungarian. In: Acta Linguistica Hungarica $45: 61-88$.

Kenesei, István 1998b. On the syntactic options of focus. Manuscript. University of Delaware and JATE, Szeged.

Kenesei, István 2009. Quantifiers, negation, and focus on the left periphery in Hungarian. In: Lingua 119: 564-91.

Lecarme, Jacqueline 1999. Focus in Somali. In: Georges Rebuschi-Laurice Tuller (eds): The grammar of focus, 275-309. John Benjamins, Amsterdam \& Philadelphia.

Lipták, Anikó 2001. On the syntax of $w h$-items in Hungarian. Doctoral dissertation, LOT, Leiden.

Mycock, Louise 2010. Prominence in Hungarian: The prosody-syntax connection. Manuscript. University of Oxford.

Olaszy, Gábor 2000. The prosody structure of dialogue components in Hungarian. In: International Journal of Speech Technology $3: 165-76$.

Ortiz de Urbina, Jon 1990. Operator feature percolation and clausal pied-piping. In: MIT Working Papers in Linguistics 13:193-208.

Puskás, Genoveva 2000. Word order in Hungarian. The syntax of A-bar positions. John Benjamins, Amsterdam \& Philadelphia.

Staudacher, Peter 2000. Partial movement and compositionality. In: Josef BayerChristine Römer (eds): Von der Philologie zur Grammatiktheorie Peter Suchsland zum 65. Geburtstag, 191-211. Max Niemeyer, Tübingen.

Surányi, Balázs 2002. Multiple operator movements in Hungarian. Doctoral dissertation, LOT, Utrecht.

Varga, László 2008. The calling contour in Hungarian and English. In: Phonology 25 : 469-97. 